\title{
ESTUDO MEDICO-LEGAL DO INFANTICIDIO
}

Deux tyrans opposés ont décidé ton sort;
L'amour, malgré l'honneur, t'a fait donner la vie,
L'honneur, malgré l'amour, t'a fait donner la mort.

M. Henault.

Diz o artigo 298 do vigente codigo penal: «Matar recem-nascido, isto é, infante, nos sete primeiros dias do seu nascimento, quer empregando meios directos e activos, quer recusando á victima os cuidados necessarios á manutenção da vida e a impedir sua morte: pena-de prisão cellular por seis a vinte e quatro annos. Parag. unico: Si o crime fôr perpetrado pela mãe, para occultar a deshonra propria: pena-de prisão cellular por tres a nove annos.

Quer pelo lado da jurisprudencia, quer pelo da medicina, o estudo do infanticidio importa multiplas e variadas questões, que, encaradas em globo ou detalhadamente, requerem meticulosa attenção.

Legislar, em materia penal, principalmente, é, para quem o faz, tarefa tâo espinhosa, que cada vez mais se reconhece a necessidade do consorcio da medicina com a sciencia do direito. Attesta-o o artigo do codigo acima enunciado, no qual, sem razão scientifica plausivel, o legislador den á palavra-recem-nascidosignificação lata de mais, em desaccordo completo com a especialidade da causa que commumente leva a mulher a matar o filho. 
Vejamos, em primeiro lugar, o que se deve entender por uma creança recem-nascida.

Se quizessemos recorrer á ethymologia da palavra (infans, que ainda não falla), o prazo de sete dias, consignado naquelle artigo, seria muito justo, como ainda o de alguns menes.

Deixemos, porém, por irrisoria, semelhante interpretação.

No empenho de util accordo, legisladores, jurisconsultos e medicos, cada qual na esphera de seus recursos, procurarão firmar a verdadeira definição da palavra-recem-nascido -, sem que comtudo chegassem a fazel-o.

Pelas disposições de diversos codigos, as divergencias são bem notaveis.

Os da Baviera (art. 159), d'Oldembourg (art. 164), da Hespanha (art. 336), reconhecem como-recemnascido - a creança que ainda não tem vivido tres dias; os de Wurtemberg, Saxonia e Brunswick, a que não tem ultrapassado vinte e quatro horas de vida; o da França (cod. civil art. 54), a creança dentro dos tres primeiros diaz, - prazo legal para a inscripção no registro civil; o de Portugal, a creança dentro de oito dias, prazo que é reduzido a dous dias pelo novo projecto de codigo; etc., etc.

A medicina, poderosa auxiliar do direito, procurou um signal anatomico, que, acceito, pudesse resolver a questão. Olivier d'Angers opinou pela quéda do cordão umbilical ; Billard, pela cicatrisação da ferida resultante do desprendimento daquelle cordão. Mas, como causas multiplas indiriduaes e extrinsecas podem influir sobre esse resultado, tornando-o precoz ou serodio, alterando, portanto, essa materialidade, o concurso prestado pela sciencia medica nenhuma luz trouxe á questão. 
A materialidade de tempo, sete dias, considerada pelo nosso codigo como o prazo dentro do qual a creança é tida como - recem-nascido-, não merece fôro de cidade.

A mulher que mata o filho dentro da ultima hora daquelle prazo, está incursa nas penas do infanticidio; a que o faz uma hora depois, nas do homicidio! Que iniquidade! Em que alterou-se, em intervallo tão curto, o effeito ligado á mesma causa?

$\mathrm{O}$ infanticidio, considerado como titulo á parte, em muitos codigos, menos no inglez e hespanhol, é tido como o homicidio voluntario do recem-nascido, circumscrevendo-se a duvida á interpretação deste termo.

Por um aresto do tribunal de Cassação, de 31 de Dezembro de 1835, infanticidio é o homicidio voluntario commettido sobre uma creança uo nascer ou em tempo muito proximo ao de seu nascimento.

As estatisticas publicadas a respeito do infanticidio, incompletas, é verdade, e deficientes, attestam que a causa que, mais frequentemente ou quasi na sua generalidade, leva a mulher a matar o filho, é occultar seu nascimento, no intuito de salvar a propria honra.

A expressão - muito proximo de seu nascimento-, consignada no aresto acima, torna clara a idéa de que se deve reputar recem-nascida a creança dentro do menor prazo possivel de vida. Os codigos de Wurtemberg, Saxonia e Brunswick, estendendo este prazo ao de vinte e quatro horas, mesmo assim, parece-nos, não satisfazem, porquanto a especialidade da causa, unica justificativa do titulo de infanticidio, a isso se oppõe. "Imagine-se uma menina, guarda zelosa do mais sagrado thesouro que possue, a honra. Tentada e seduzida por um homem,- - de pura e immaculada, até então, vê-se deshourada. Tempo depois, alguma cousa passa-se no seu organismo; ella reconhece-se 
gravida. ()s fulgidos sonhos que lhe povoavam a mente, eil-os substituidos pela idéa tetrica da desgraça, que a espreita. A ira desoladora dos paes, o desprezo dos parentes e amigos, o ferro ern brasa da deshonra que combure-lhe a existencia, tudo faz-lhe despertar o desejo imperioso de salvaçâo. Tenta o aborto, mas debalde. Approxima-se o momento do parto, que se processa clandestinamente. Nasce o filho; e, antes que este se denuncie, mata-o. Desapparece o corpo de delicto de sua deshonra».

Nào deixa bem transparecer o exemplo acima, que só em tempo muito proximo do nascimento, é que se deve considerar a creança como recem-nascido? Desde quando a mulher, contemplando o filho, embora illegitimamente gerado, quizesse matal-o na metade do tempo, mesmo, consignado nos codigos de Wurtemberg, Saxonia e Brunswick, quem desconhece a luta que se travaria entre 0 instincto materno, que exige a conservação, e o sentimento de honra, que pede a destruição? N'essa luta, não se póde negar, o amor de mãe vencerá os reclamos sociaes.

Se nos fosse permittido, e se não opinassemos que a outrem, que não o medico, incumbe fazel-o, aquella expressão - muito proximo-- nós a estendiriamos ao prazo maximo de uma hora, como sendo aquelle dentro do qual se deve considerar a creança-recemnascido-, por ser justamente o prazo no qual ella recebe os primeiros cuidados, de accordo com as opiniões de Froriep, Werner e Ganz, que consideram como tal a creanca logo an nascer ou antes de receber os primeiros cuidados.

Antes da promulgação do vigente codigo penal, na regra do formulario do processo, seguida até então, se perguntava - se a creança viveu e quantas horas. Esta pergunta - quantas horas - não exprime claramente que só no menor prazo possivel, se deve 
consideral-a como recem-nascida? Se assim não fossc, porque em lugar de-quantas horas - não se disse - quantos dias -, ou então - quanto tempo?

Estas ultimas reflexões que emanam do illustrado Sr. J)r. Souza Lima, nós as subscrevemos em apoio de nossa opinião.

Aos tribunaes superiores, á jurisprudencia, em summa, cumpre resolver a questão, parecendo-nos rasoaveis as legislações ingleza e hespanhola, considerando o infanticidio como uma das modalidades do homicidio.

\section{$\S$}

Afastam-se da nossa competencia as considerações que vamos fazer.

Mas, não nos pudemos eximir da necessidade de darmos as razões, pelas quaes julgamos uma superfetação o titulo de infanticidio, nos codigos penaes, onde, a proposito do homicidio, o assassinato de um recem-nascido tem todo o cabimento, aggravado ou excusado, segundo as circumstancias que o cercarem.

No art. 294 (homicidio) o nosso codigo pune com a pena de prisão cellular por 12 a 30 annos, 0 crime de morte perpetrado com qualquer das circumstancias aggravantes, mencionadas nos parags.

. e o $90^{\circ}$, o qual diz - ter sido o crime commettido contra ascenciente, DESCENDENTE, conjuge, etc. No art. 298 (infanticidio) pune o crime com a pena de prisâo cellular por 6 a 24 annos, degradando-a para 3 a 9 annos nos casos em que a mãe fôr autora, para occultar a deshonra.

Por ventura a qualidade de - recem-nascido-exclue a victima de partilhar do caracter de - descendentedo parag. $9 .^{\circ}$ do artigo 294 ? Se bem que no art. 298 o crime seja punido com penas menores, em que isto 
vem alterar o genero - homicidio - ? Não seria mais logico fazer incidir o caso no genero, considerando como especie o parag. unico do mesmo art. 298?

A necessidade de maior protecção, pela nenhuma resistencia que possa offerecer a victima, como ainda sua menor quantidade politica, nada disto julgamos poder servir de medida differencial entre os dous crimes.

O alarma social, attondendo-se ainda á especialidade da causa, é quasi nullo, ou nullo, porquanto o assassinato do - recem-nascido-e é commettido clandestinamente, antes de notorio seu nascimento.

Alguns criminalistas, como Carrara e Balestrini, consideram a causa honoris como determinante deste crime sui generis, destacado do homicidio: outros, porém, consideram essa causa unicamente como excusa que degrada a pena.

Nâo escrupulisamos em acceitar esta ultima opinião. Effectivamente o substratum juridico sobre o qual assenta o assassinato de um recem-nascido, illegitimamente gerado, caso unico do infanticidio, é o prompto desapparecimento dos traços de sua existencia pro honore. Só assim esse titulo teria sua razão de ser, evitando-se o absurdo de uma prostituta ou uma reincidente, como apresenta Ferriani um caso, que matando o filho recem-nascido, comparticipe da brandura da pena, que a lei decretou para uma mãe desventurada.

Este favor da lei, segundo Balestrini, deve aproveitar tambem aos parentes mais proximos, porquanto da nodoa daquella partilham estes.

Conclue-se destas rapidas considerações:-a) que a palavra - recem-nascido - de interpretação tão controvertida, deve ser definida por outrem, que não o medico, correndo sua significação por conta dos juizes, conforme affirmam Carrara, Balestrini, Puglia, 
Mittermaier e outros ; b) que o prazo maximo de uma hora que dissemos acima dever considerar-se como o limite do recem-nascimento, embora constitua uma materialidade variavel, todavia, exprimindo o tempo no qual a creança deve receber os primeiros cuidados, não póde deixar de abranger assim a significação desse termo; c) que o titulo de infanticidio, considerado crime á parte do homicidio, não tem razão de ser, salvo nos casos - pro honore-, podendo, mesmo assim, incidir naquelle genero como especie.

\section{$\S \S$}

Viver é respirar; não ter respirado é nâo ter vi. vido (Casper).

Eis a doutrina fundamental do infanticidio.

Ao passo que no aborto criminoso, que, segundo Tardieu, é - a expulsão prematura e violentamente provocada do producto da concepção, independentemente de toda circumstancia de edade e de conformação-não se exige a presença do corpo de delicto, como prova desta figura juridica, cujo titulo, digamos logo, deve ser substituido pelo de feticidio, como opina a sciencia moderna do direito penal; no infanticidio, esse corpo de delicto torna-se obrigatorio, porquanto é ao cadaver do-recem-nascido - que a pericia medica vae pedir as provas da respiração, condição essencial deste crime, cuja existencia se tem de provar.

$\mathrm{E}$, de tal gravidade esta prova, que só muito depois de maduramente reflectir, depois de reunir todos os dados, é que ella deve concluir de accordo com as premissas estabelecidas. Para isto tudo põe em contribuição, evidenciando-se, assim, nossa asserção de que a medicina é uma poderosa auxiliar do direito; 
ou que a medicina-legal é, segundo Marc, - a applicação dos conhecimentos medicos aos casos de processo civil e criminal, que podem ser por ella esclarecidos. - O juiz tem necessidade de exigir essa prova da respiração extra-uterina, ampla, franca, completa, para sobre ella assentar seu julgamento.

De todas as docimasias (palavra que vem do grego e significa - provar) a que resistio a todas as objecções, mesmo as mais sérias, foi a pulmonar hydrostatica de Galeno, cujo valor scientifico é inconcusso. Além desta, ha algumas outras docimasias, taes como a de Ploucquet, a de Daniel, a pneumo-hepatica de Puccinotti, a pneumo-cardiaca de Orfila, a hepatica de Buttner, a vascular, a de Bernt, etc., as quaes pouca ou nenhuma luz trazem á questão.

No entanto, outras ha que não tendo o brilho da - pulmonar hydrostatica de Galeno, não deixam de subsidia-la, e, pois, são dignas de menção. Referimo-nos á - docimasia diaphragmatica - a renal, caracterisada pela presença de acido urico nos rins - a gastro-intestinal ou a de Breslau.

Não nos é possivel, em trabalho tão despretencioso, dar a descripção de todas essas provas, critical-as e mostrar o quanto não satisfazem: apenas, affirmamos que a primeira, a de Galeno, é a que propugna pela verdade, é a que projecta mais brilho sobre a questão.

Uma objecção se tem feito: A sciencia apresenta casos de creanças nascerem a termo, vivas e sem respirar. Depaul affirma ter visto algumas, que não começaram a respirar senão duas horas depois do parto. Acceitemos, sem commentar, o exemplo e digamos se nestas condições, a morte violenta constitue ou não o crime de infanticidio, desde que a prova da respiração é negativa.

Não ha duvida que o facto póde dar-se; como tambem que a respiração é a prova luminosa, que se 
exige, da vida extra-uterina, em tal assumpto. Mas, tambem é verdade que a sciencia possue meio de reconhecimento dessa vida, sem respiração.

Este meio é a coagulação do sangue. Tal facto encontrou impugnação por parte de alguns, entre os quaes Brouardel, o qual sustenta que o sangue extravasado em cavidade serosa, como o peritoneo, geralmente não coagula-se, bem como o que corre de uma ferida feita em vida, algumas vezes, apoiando-se para isto affirmar, no que acontece com os alcoolistas.

A' vista do exposto, desde que esse meio, a coagulação do sangue, não póde sempre ser considerado um facto certo, o recurso, desde que provar-se que a creança não respirou, é concluir que ella não viveu.

Mas, nascida a creança, nestas condições, fracturando-se-lhe o craneo, verificando-se que estas fracturas, por sua posição e disposição, foram violentumente feitas, encontrando-se o sangue coagulado, depois de extravasado, porque não affirmar-se o infanticidio, mesmo com a prova negativa da respiração? Taes lesões não attestam o crime em toda a sua hediondez? Não ha negal-o.

Mas, como em materia tão interessante e compromettedora, se exige uma prova certa da vida-a respiração---para se concluir sobre a morte, eis a razão da sentenciosa proposição acima dita - viver é respirar; não ter respirado é não ter vivido.

Dr. Amancio de Carualho. 